\title{
Characterisation of the protein corona using tunable resistive pulse sensing: determining the change and distribution of a particle's surface charge
}

\author{
Emma L. C. J. Blundell ${ }^{1} \cdot$ Matthew J. Healey $^{1} \cdot$ Elizabeth Holton $^{1}$. \\ Muttuswamy Sivakumaran $^{2} \cdot$ Sarabjit Manstana $^{3} \cdot$ Mark Platt $^{1}$
}

Received: 7 March 2016 /Revised: 27 April 2016/Accepted: 31 May 2016 /Published online: 10 June 2016

(C) The Author(s) 2016. This article is published with open access at Springerlink.com

\begin{abstract}
The zeta potential of the protein corona around carboxyl particles has been measured using tunable resistive pulse sensing (TRPS). A simple and rapid assay for characterising zeta potentials within buffer, serum and plasma is presented monitoring the change, magnitude and distribution of proteins on the particle surface. First, we measure the change in zeta potential of carboxyl-functionalised nanoparticles in solutions that contain biologically relevant concentrations of individual proteins, typically constituted in plasma and serum, and observe a significant difference in distributions and zeta values between room temperature and $37^{\circ} \mathrm{C}$ assays. The effect is protein dependent, and the largest difference between the two temperatures is recorded for the $\gamma$-globulin protein where the mean zeta potential changes from -16.7 to $-9.0 \mathrm{mV}$ for 25 and $37{ }^{\circ} \mathrm{C}$, respectively. This method is further applied to monitor particles placed into serum and/or plasma. A temperature-dependent change is again observed with serum showing a $4.9 \mathrm{mV}$ difference in zeta potential between samples incubated at 25 and $37^{\circ} \mathrm{C}$; this shift was larger than that observed for samples in plasma $(0.4 \mathrm{mV})$. Finally, we monitor the kinetics of the corona reorientation for particles initially
\end{abstract}

Electronic supplementary material The online version of this article (doi:10.1007/s00216-016-9678-6) contains supplementary material, which is available to authorized users.

Mark Platt

m.platt@lboro.ac.uk

1 Department of Chemistry, Loughborough University, Loughborough LE11 3TU, UK

2 Peterborough City Hospital, Edith Cavell Campus, Bretton Gate, Peterborough PE3 9GZ, UK

3 Human Genomics Lab, Centre for Global Health and Human Development, School of Sport, Exercise and Health Sciences, Loughborough University, Loughborough, UK placed into serum and then adding $5 \%(V / V)$ plasma. The technology presented offers an interesting insight into protein corona structure and kinetics of formation measured in biologically relevant solutions, i.e. high protein, high salt levels, and its particle-by-particle analysis gives a measure of the distribution of particle zeta potential that may offer a better understanding of the behaviour of nanoparticles in solution.

Keywords Biosensor · TRPS · Zeta potential · Protein corona $\cdot$ Tunable pores

\section{Introduction}

In recent years, synthesis methods for nanoparticles have evolved to the extent that particle size, shape and composition can be easily modified [1-4] and this had led in turn to great advances in the field of diagnostics [5, 6], drug delivery [7-9] and technology platforms $[10,11]$. With the desire to understand and improve nanomaterials comes a need for characterisation platforms to offer rapid analysis of size, charge and shape. Ensemble techniques that take measurements on several particles simultaneously and provide an average measurement can underestimate subpopulations within multimodal samples $[12,13]$, and a raft of technologies have appeared to help tackle this $[14,15]$. Such technologies now offer an ability to quantify the population of particles with single particle resolution building an understanding that not all particles are created equal and there exists distributions such as particle size or ligand density.

One such technology is based on the Coulter Counter principle, referred to as resistive pulse sensing (RPS) [16-18]. The technique allows the characterisation of proteins, inorganic ions, colloids and nanoparticles within their natural environment. Two categories of resistive pulse sensors exist 
that utilise either biological $[19,20]$ or inorganic nanopores [21-23]. Here, we describe a recent adaptation to inorganic pores that uses a tunable elastomeric pore termed tunable resistive pulse sensing (TRPS) [14, 24-36]; the pore can be stretched in real time to suit the sample. The brief setup and theory for TRPS technologies is as follows: A stable ionic current is established by two electrodes, separated by a pore; as particles/analytes translocate the pore, they temporarily occlude ions, leading to a transient decrease in current known as a 'blockade event', examples of which can be seen in Fig. 1. In the TRPS arrangement used here, the pore is mounted laterally so that particles typically move from the upper fluid cell into the lower fluid cell, aided by an inherent pressure head due to $40 \mu \mathrm{l}$ of liquid in the upper fluid cell of approximately $50 \mathrm{~Pa}$ [35]. By monitoring changes in blockade width, blockade magnitude $\left(\Delta i_{p}\right)$ and blockade frequency (events/min), it is possible to elucidate the zeta potential, size and concentration of colloidal dispersions in situ [14, 37, 38]. By controlling the aspect ratio of the pore, resistive pulse sensors have been used to measure analytes that range from single molecules, DNA, proteins, cellular vesicles to cell bacteria and viruses; detailed reviews on the types of analytes and applications can be found elsewhere [24, 36, 39, 40]. TRPS is becoming an increasingly common variation of RPS for the characterisation of biological and inorganic nanomaterials $[24,36]$ and since its conception has been tested against alternative technologies such as DLS/
PALS [14, 15, 41-44], TEM [33], and ultracentrifugation [44] for the characterisation of nanomaterials $[15,45]$.

The how and where of measuring the properties of particles are important to consider as changing $\mathrm{pH}$, ionic strength or temperature, or purifying particles can give a misrepresentation of their behaviour in their natural environment. In the case of nanomaterials that are intended to be used in vivo, it is not properties within synthesis processes that determine their biological activity, but how they interact with proteins upon entering the body. Upon the addition of nanoparticles to biological fluids, there is an almost immediate fouling of their surfaces with proteins, peptides and other cellular apparatus forming a layer known as the protein corona [46-48]. The composition of the corona has been shown to determine the eventual properties of the particles [49-51] and has been reported as critically affecting pathophysiological effects of nanoparticles [52]. The structure of the protein corona can be dynamic and complex and is different for particles of the same composition but with different surface chemistries and size in the same solution $[46,53]$. Detailed studies of the corona have been performed using an array of technologies including mass spectroscopy $[54,55]$. Various techniques have been used to look at a range of specificities of protein coronas, for example, protein corona thickness has been investigated using ensemble techniques such as dynamic light scattering (DLS) and differential centrifugal sedimentation
Fig. 1 Particles in the presence of human plasma and serum showing the formation of both a 'hard' and 'soft' protein corona. $\mathrm{I}_{1.0}, \mathrm{I}_{0.8}, \mathrm{I}_{0.6}, \mathrm{I}_{0.4}, \mathrm{I}_{0.2}$ represent the position of the particle as it translocates the pore (where $\mathrm{I}_{1.0}$ is the narrow pore entrance) and are relative to $\mathrm{T}_{1.0}, \mathrm{~T}_{0.8}, \mathrm{~T}_{0.6}, \mathrm{~T}_{0.4}$, $\mathrm{T}_{0.2}$, which represent the time taken (ms) for the particle to reach that position. $T_{1.0}$, is equivalent to $\mathrm{dR}_{\max }$ when the blockade event is at $100 \%$ magnitude; $\mathrm{T}_{0.8}, \mathrm{~T}_{0.6}$, $\mathrm{T}_{0.4}, \mathrm{~T}_{0.2}$, correspond to when the blockade is $80,60,40$, and $20 \%$ of its $\mathrm{dR}_{\max }$ and indicates the particle traversing the pore

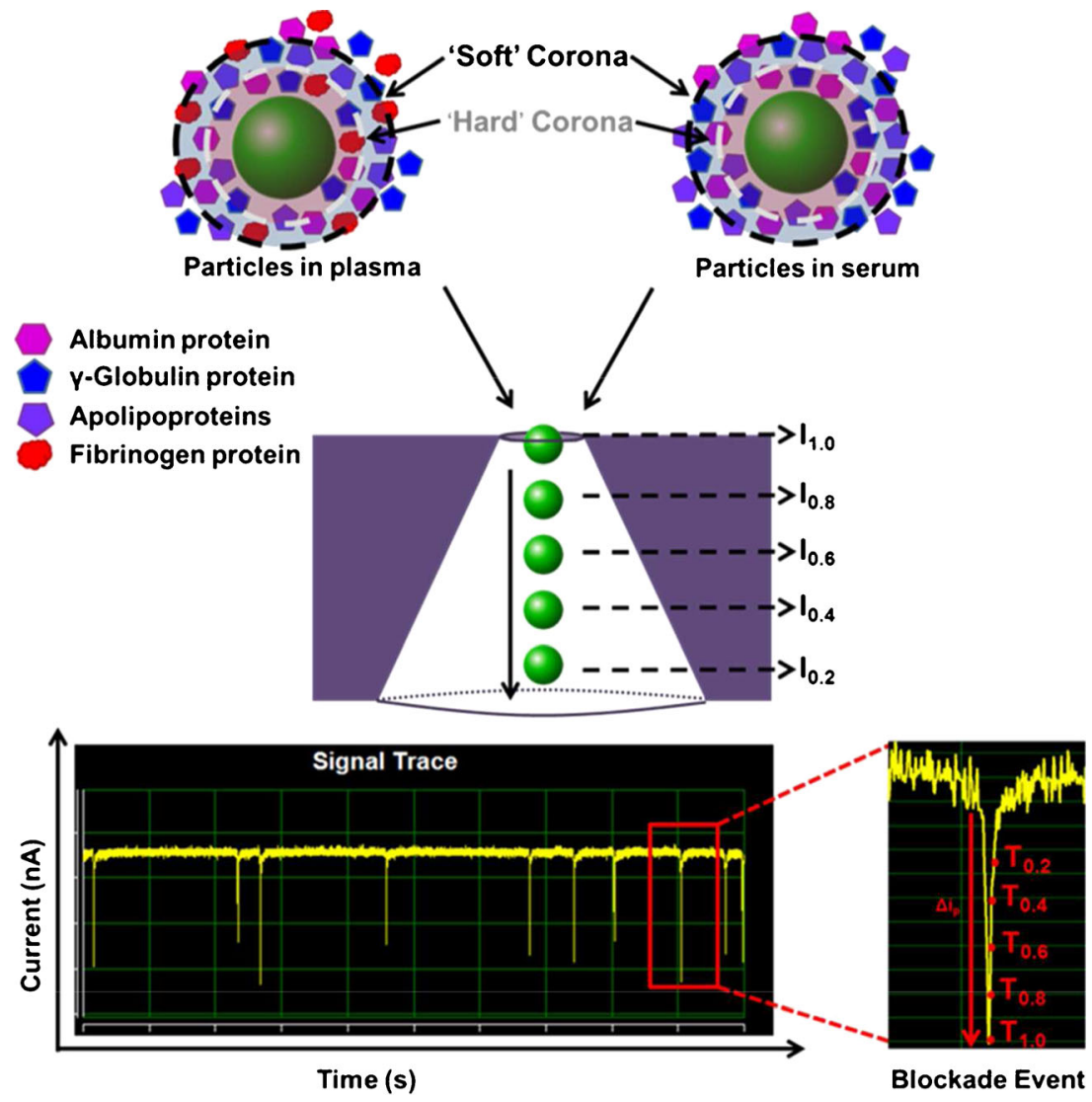


(DCS) $[49,56]$. Protein corona conformation has been studied using circular dichroism (CD) and fluorescence quenching [57, 58]; the affinity has also been a popular characterisation property of protein coronas and has previously been measured using size exclusion chromatography (SEC), surface plasmon resonance (SPR) and isothermal calorimetry (ITC) [49, 56, 59]. A frequent and easy value used to characterise the corona is zeta potential $[46,48,50,54,60]$. The zeta potential represents the value of the electrostatic potential at the plane of shear, and typically for nanoparticle systems, zeta potential values of $\pm 30 \mathrm{mV}$ are representative of stabilised particles [61].

When nanoparticles are introduced to biological fluids, the protein corona is formed in a series of layers, otherwise known as the 'hard' and 'soft' corona. Proteins forming the hard corona are those with a higher affinity that interact directly with the nanoparticle surfaces, whereas proteins forming the soft corona are those engaging in weaker protein-protein interactions with the hard corona $[56,62]$. It has previously been found that a vast range of particles bind successfully to apolipoproteins in physiological fluids [55]. Formation of a protein corona alters the size, aggregation properties and surface properties of nanoparticles [63], thus creating a new biological distinctiveness for further application. There are 5 main components that define the composition of a protein corona: thickness and density, identity and quantity, orientation, conformation and affinities [63].

Protein adsorption kinetics play a prominent role in this study and are key to understanding the binding mechanisms that will occur in a natural environment. Although this process is time-dependent, the kinetics rely on $k_{\text {on }}$ and $k_{\text {off }}$ parameters, indicating the rate constants for adsorption and desorption of proteins. $k_{\text {on }}$ is largely dependent on how often the protein contacts the nanoparticle surface, as well as the probability of successful binding between the two materials [64]. The strength of the protein-nanoparticle interaction defines $k_{\text {off }}$ [64], and a strong, high-energy interaction will exert a low $k_{\text {off }}$ value. Understanding the kinetics of formation and protein corona composition is important to understand processes nanoparticles may undertake when introduced into the body and into physiological conditions.

Here, we present a protocol for the rapid analysis of the corona zeta potential and demonstrate its versatility by making the measurement in solutions that mimic the natural environment, i.e. high ionic strength and high protein composition. By making comparable measurements of carboxyl polystyrene nanoparticles in a range of incubation temperatures and with different proteins, a clear difference in magnitude and variation of zeta potential within the particle population was observed; the three proteins chosen to demonstrate this are the most predominant (in terms of quantity) proteins in normal human plasma and we perform the experiment concentrations that would reflect normal plasma. The ability to have individual particle resolution provides an opportunity to see the full variation of zeta potential in a single sample. The findings highlight the need to monitor the protein corona and its formation at biologically relevant temperatures and suggest that the kinetics of protein adsorption and spread in zeta potential values varies for each of the proteins and biological mediums studied. Finally, we show the scope of the technology by monitoring the change in the hard and soft corona elements interacting with the particles through incubation in serum, followed by the addition of a small amount $(5 \%(V / V))$ of plasma. It is known that protein components of a higher concentration or affinity to the particle can remove and restructure the soft corona that is formed in biological fluid [55], and we monitor the rate of this change and the kinetic effects that eventually settle on a new zeta potential value.

\section{Materials and methods}

\section{Chemicals and reagents}

The initial buffer used for particle analysis was phosphate buffered saline $(1 \times$ PBS tablet $(0.01 \mathrm{M}$ phosphate buffer, $0.0027 \mathrm{M}$ potassium chloride, $0.137 \mathrm{M}$ sodium chloride) in $200 \mathrm{~mL}$ deionised water (18.2 M $\Omega \mathrm{cm})$ ). PBS tablets (P4417) were purchased from Sigma-Aldrich, UK.

\section{Carboxyl polystyrene standards}

Carboxylated polystyrene particles, denoted as CPC200, with a mean nominal diameter of $210 \mathrm{~nm}$ and stock concentration of $1 \times 10^{12}$ particles $/ \mathrm{mL}$, were purchased from Bangs Laboratories, USA and used as a calibrant for zeta potential analysis, as well as the sample particles. CPC200s were vortexed for $30 \mathrm{~s}$ followed by a 2 min sonication to ensure monodispersity prior to any TRPS analysis or sample incubation.

\section{Isolated proteins}

All isolated proteins studied were purchased from SigmaAldrich, UK, without modification or purification unless stated otherwise: fibrinogen from human plasma (F3879), albumin from human serum (A9511) and $\gamma$-globulin from human blood (G4386).

\section{Human plasma and serum samples}

Blood samples were collected and prepared at Peterborough City Hospital Pathology Laboratory, UK. Plasma collection was completed using blood from a healthy volunteer donor that was collected in citrate medium (Sarstedt, UK.) and centrifuged at $3000 \mathrm{rpm}$ for $8 \mathrm{~min}$. Serum was gathered using blood from a healthy volunteer donor that was collected into a Sarstedt monovette/collection tube, and was centrifuged at 
$3000 \mathrm{rpm}$ for $6 \mathrm{~min}$. The supernatants from each sample were transferred into separate sample vials and stored at room temperature prior to use.

\section{Isolated protein studies}

Using PBS buffer, isolated albumin, fibrinogen and $\gamma$ globulin samples were prepared to give the following concentrations: $43,3.2$ and $20 \mathrm{~g} / \mathrm{L}$, respectively, as to mimic protein concentrations found in human blood. The concentrations of proteins were measured from human plasma and serum samples. The samples used in this study were analysed by an Instrument Laboratory ACL TOP CTS500 coagulation analyser (Werfen, Spain) to obtain the fibrinogen concentration. Albumin and immunoglobulin levels were taken from test serum samples that were analysed by a Roche Cobas Biochemistry Analyser (Roche Diagnostics, Switzerland). CPC200s were added resulting in a final concentration of $1 \times 10^{10}$ particles $/ \mathrm{mL}$. Each sample was vortexed for $30 \mathrm{~s}$ and sonicated for $1 \mathrm{~min}$ before incubation. Samples were then incubated at 25 and $37{ }^{\circ} \mathrm{C}$ in a mini dry bath (Benchmark Scientific, USA) for $10 \mathrm{~min}$ prior to TRPS analysis.

\section{Serum and plasma studies}

Human plasma and serum were prepared immediately before the experiments to minimise ex vivo artefactual changes. The prepared plasma and serum were separately diluted 10-fold with PBS before CPC200s were added to both samples resulting in a final particle concentration of $1 \times 10^{10}$ particles $/ \mathrm{mL}$, herein these solutions are referred to as serum and plasma. Samples were vortexed for $30 \mathrm{~s}$ and sonicated for 1 min, followed by incubation in a mini dry bath (Benchmark Scientific, USA) at 25 and $37^{\circ} \mathrm{C}$ for $10 \mathrm{~min}$ before being removed for TRPS analysis. It should be noted that it is possible for some proteins in human plasma and serum to interact and adsorb onto the pore walls; therefore, a control measurement of CPC200s in PBS (of known zeta potential, $-20 \mathrm{mV}$ ) was completed before and after each protein/ plasma/serum sample to establish if any changes had occurred to the pore itself.

\section{Plasma spiking assay}

Human serum was $10 \times$ diluted in PBS before CPC200s were added to a final concentration of $1 \times 10^{10}$ particles $/ \mathrm{mL}$. Samples were vortexed for $30 \mathrm{~s}$ and sonicated for $1 \mathrm{~min}$ before being incubated for $10 \mathrm{~min}$ at 25 and $37{ }^{\circ} \mathrm{C}$ in a mini dry bath (Benchmark Scientific, USA). At $10 \mathrm{~min}, 5 \%(V / V)$ human plasma was added to the serum samples and the samples were vortexed for $30 \mathrm{~s}$. TRPS measurements were completed once the plasma had incubated with the serum sample for 5, 10, 15, 20,30 and $60 \mathrm{~min}$.

\section{Tunable resistive pulse sensing}

All measurements were completed using the qNano (Izon Science Ltd, NZ). The system utilises tunable nanopores with propriety data capturing software (Izon Control Suite v3.1.2.53). In all experiments, the lower fluid cell contained $80 \mu \mathrm{L}$ of PBS buffer, ensuring no bubbles were present. When a sample measurement was being taken, the upper fluid cell contained $40 \mu \mathrm{L}$ of the sample (suspended in PBS buffer). After each measurement was taken, the nanopore was washed several times by removing and replacing $40 \mu \mathrm{L}$ of buffer, each time applying varied pressures until no particles were observed. This was performed several times to remove any residual particles in the system and thus ensure no crosscontamination between samples. The nanopores used throughout all experiments were capable of detecting particles within the size range of 100-300 $\mathrm{nm}$ (as stated by the manufacturer, Izon Science Ltd) and denoted as an NP200. To account for the variation in the manufacturing of the nanopores, appropriate stretch (44-46 $\mathrm{mm}$ ), voltage and pressure were applied in all experiments; the conditions were matched as to the blockade magnitudes of CPC200s in PBS being of a similar size throughout all experiments. All samples were vortexed for $30 \mathrm{~s}$ and sonicated for $2 \mathrm{~min}$ prior to analysis.

\section{Zeta potential measurements using TRPS}

When carrying out zeta potential measurements, the nanopore stretch was kept the same for a particular dataset and nanopore between calibration and sample measurements. To calibrate a nanopore for zeta potential analysis, the calibration particles, of known size and zeta potential, were measured in PBS at 3 applied voltages; the particles measured at the highest voltage were measured at 2 external pressures (in addition to the inherent $47 \mathrm{~Pa}$ pressure head on the system). When running the samples, the blockade magnitudes were ensured to be at least $100 \times$ larger than the respective background noise of ca. $10 \mathrm{pA}$. In accordance with the calibration runs, the samples were run at the highest calibration voltage. Calibration measurements were completed when a new nanopore (NP200) was introduced to ensure conditions were matched so the blockade magnitudes of CPC200s in PBS were of a similar size to other NP200s used for this study. A CPC200 sample in PBS was run after each protein/plasma/serum sample to ensure the zeta potential of the pore remained unchanged and as such did not affect the measured zeta potential of further samples.

\section{Results and discussion}

Zeta potential values were determined from the particle velocities as they traversed the nanopore; a full description of the protocol and theory can be found elsewhere [21, 38]. Briefly, 
the duration of particle translocation is measured as a function of applied voltage, taking an average electric field and average particle velocities over the entire sensing zone that is a regular conical pore. Each particle's electrophoretic mobility is derived from $1 / T$, where $T$ is the blockade duration and voltage, multiplied by the square of the sensing zone length, $L$, as part of a calibration constant. Figure 1 shows the conical sensing zone and an example of the blockade duration times, $T$, as a result of a blockade event at various positions, $I$, in the nanopore. $T_{1.0}$ for example is equivalent to when the blockade is $100 \%$ in magnitude and is indicative of $I_{1.0}$, the position to which the particle is approaching the pore entrance. $T_{0.6}$ relates to position $I_{0.6}$ where the blockade is $60 \%$ in magnitude and the particle has traversed $40 \%$ of the pore. It is important to note each blockade depicted in the signal trace is indicative of a single particle as it passes through the pore, highlighting the advantages of using particle-by-particle technologies such as TRPS.

Average velocities determined across multiple reference points within the nanopore vastly reduce any errors in this zeta potential calculation process [38]. The calibration of the pore itself is based on a linear relationship between $1 / T$ and voltage, $V$, at each blockade reference point. Equation 1 shows the direct relationship between particle velocities and their zeta potentials, $\left(v_{x}\right)_{e l \mathrm{Cal}}$ and $\left(v_{x}^{i}\right)_{\text {el Sample }}$ are the particle velocities of calibration and sample particles, respectively, and $\xi_{\text {net Cal }}$ and $\xi_{x \text { net Sample }}^{i}$ represent their zeta potential values [38].

$\frac{\left(v_{x}^{i}\right)_{e l ~ S a m p l e}}{\left(v_{x}\right)_{\text {el Cal }}}=\frac{\xi_{x \text { net Sample }}^{i}}{\xi_{\text {net } \text { Cal }}}$

Equation 2 shows the zeta potentials measured at each of the blockade reference points can then be used to determine the zeta potential of each individual particle, $i$, as it passes through the pore, $\xi_{\text {Sample }}^{i}$.

$$
\begin{aligned}
& \xi_{\text {Sample }}^{\mathrm{i}}=\frac{\sum_{\mathrm{x}} \xi_{\mathrm{x}}^{\mathrm{i}} \text { Sample }}{\sum_{\mathrm{x}}} \\
& =\frac{\sum_{\mathrm{x}}\left(\mathrm{v}_{\mathrm{x}}^{\mathrm{i}} \text { Sample }^{-} \mathrm{v}_{\mathrm{x}}^{\mathrm{P}} \text { Cal } \times P\right) /\left(\mathrm{v}_{\mathrm{x} \text { Cal }}^{\mathrm{V}} \times V\right)}{\sum_{\mathrm{x}}} \\
& \times \xi_{\text {net } \mathrm{Cal}}+\xi_{\mathrm{m}}
\end{aligned}
$$

Where $\mathrm{v}_{\mathrm{x} \mathrm{Cal}}^{\mathrm{V}}, \mathrm{v}_{\mathrm{xCal}}^{\mathrm{P}}, P$ and $V$ are electrokinetic velocity per unit voltage, convective velocity per unit pressure, applied pressure and voltage, respectively. $I_{x}$ is the position of the particle in the nanopore after time $t=T_{x}, v_{x}^{i}$ Sample is the sum of the particle velocities at relative positions, $l_{x}$ [38].

The proteins used in this study were chosen based on their relative abundances in both blood plasma and serum samples. Albumin and $\gamma$-globulin are present in both plasma and serum samples at approximately 4 and $2 \%$, whereas fibrinogen (as well as other clotting factors) is only found in plasma at approximately $0.4 \%$. Zeta potential values measured for particles incubated with each of the isolated proteins are shown in Fig. 2 (for reference the starting zeta potential of a CPC200 in PBS is $-20 \mathrm{mV})$.

When the particles were incubated with each of the proteins separately at $25^{\circ} \mathrm{C}$, both fibrinogen and $\gamma$-globulin showed a relatively small change in mean zeta potential from particles in PBS buffer, differences of 3.2 and $3.6 \mathrm{mV}$, respectively. The size and zeta potential distributions of CPC200 carboxyl particles in PBS are shown in Fig. 3. Albumin was seen to have a much larger effect on the particle zeta potentials at $25^{\circ} \mathrm{C}$ as the zeta values were reduced by $9.2 \mathrm{mV}$ from the PBS control. Albumin was at the highest concentration at $40 \mathrm{~g} / \mathrm{L}$ in comparison to the fibrinogen and $\gamma$-globulin samples only having protein concentrations of 4 and $20 \mathrm{~g} / \mathrm{L}$ respectively. The protein concentrations were chosen to replicate the typical composition usually found in the human body, although it should be noted that the concentration of proteins to that of the particles in each experiment was always in a large excess as to coat each surface of every particle. The proteins were also investigated at a constant concentration $(5 \mathrm{~g} / \mathrm{L})$ at a $25{ }^{\circ} \mathrm{C}$ incubation temperature for $10 \mathrm{~min}$ to determine whether protein concentration had an effect on the protein corona on the particles, results of which are shown in the Electronic Supplementary Material (ESM), Fig. S1. From this, it was found that the relative change in zeta potential (from a control of the particles just in PBS) was smallest for fibrinogen and $\gamma$ globulin with values of 4.3 and $4.9 \mathrm{mV}$, respectively. The largest change in zeta potential was again observed for the albumin protein with a difference of $8.9 \mathrm{mV}$. These comparable changes show the results are protein specific and not related to the concentration at these levels. It was therefore expected that the proteins would adsorb onto the particle surface, forming the protein corona. Any such protein corona would change the surface charge density on the particles and be measured by a change in particle velocity, which in turn is plotted as the zeta potential. At $25^{\circ} \mathrm{C}$, the small zeta potential changes for fibrinogen and $\gamma$-globulin samples are more than likely because of the protein isoelectric points and their behaviour at physiological $\mathrm{pH}$. Albumin has an isoelectric point of 4.7 whereas fibrinogen and $\gamma$-globulin have isolectric points of 5.8 and 6.6, respectively [65]. Previous reports have found that as the adsorption $\mathrm{pH}$ moves away from the protein isolectric points, the adsorbed molecules will occupy a larger area of the surface. This is due to internal electrostatic repulsions and thus a lower structural stability [66]. Our samples were all suspended in PBS buffer at $\mathrm{pH} 7.4$, and therefore, the albumin is expected to occupy the largest area of the nanoparticle surface as the adsorption is occurring at a $\mathrm{pH}$ furthest from its isoelectric point. This may be the reason the albumin shows the largest change in zeta potential after a $25^{\circ} \mathrm{C}$ 


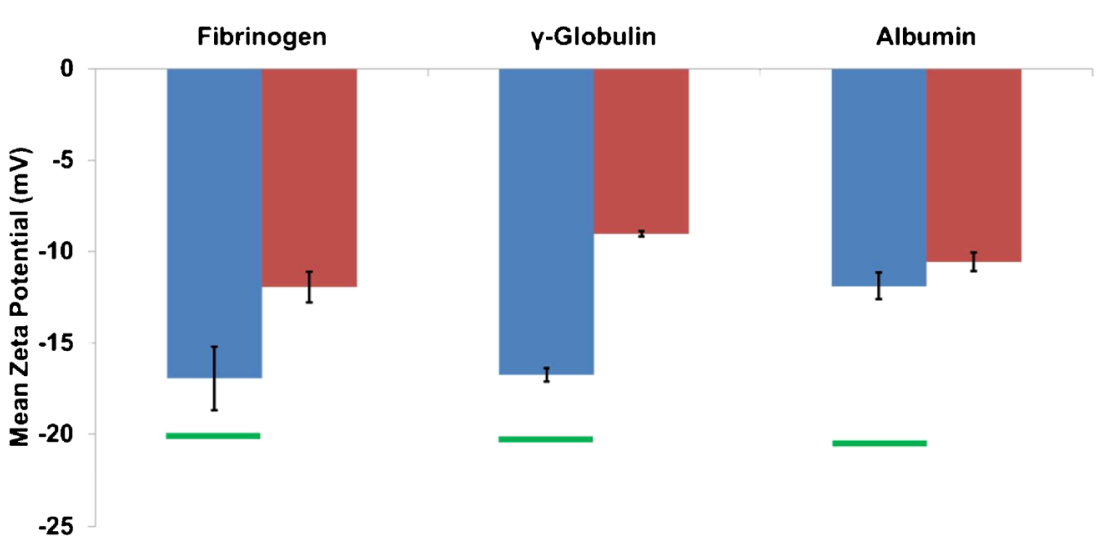

Fig. 2 Mean zeta potential $(\mathrm{mV})$ versus the protein the particles were incubated with. The blue bars show results for a 10-min particle incubation at $25^{\circ} \mathrm{C}$ and the red bars show the mean zeta potential values for particles incubated with the proteins for $10 \mathrm{~min}$ at $37^{\circ} \mathrm{C}$. The green lines represent the measured mean zeta potential for calibration particles of

incubation in comparison to the smaller changes observed for fibrinogen and $\gamma$-globulin (isoelectric points closer to 7.4).

Particles were also incubated with each of the proteins at a higher temperature of $37^{\circ} \mathrm{C}$; it was hypothesised that as the proteins are present in such a large excess that the incubation time of 10 min would be enough to coat the particles with a monolayer of protein, and that the temperature would have little effect on the result. In contrast, at $37{ }^{\circ} \mathrm{C}$, there were significant differences from values at $25^{\circ} \mathrm{C}$ and each protein produced varying shifts in zeta potential values. At the elevated temperature, $\gamma$-globulin was seen to have the largest reduction in zeta potential from a value of $-20.3 \mathrm{mV}$ (particles in PBS) to $-9.0 \mathrm{mV}$. This is of particular interest as these results indicate each protein interacts with the particle surface uniquely, having direct implications on the particle zeta potential. $\gamma$ Globulin also showed the largest change in zeta potential as a

a

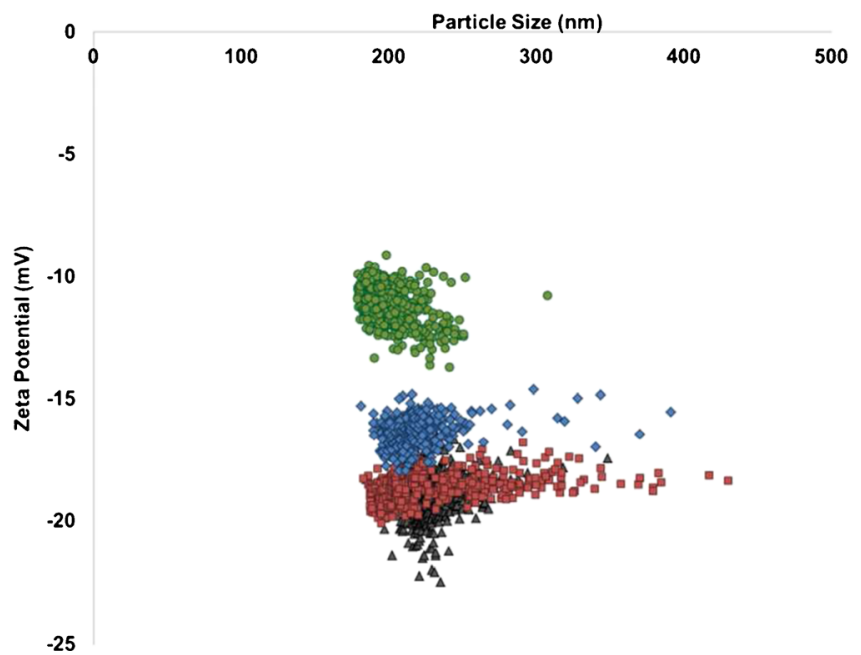

Fig. 3 Zeta potential $(\mathrm{mV})$ versus particle size $(\mathrm{nm})$. The red, blue and green datasets are zeta potential distributions for CPC200s incubated for 10 min with fibrinogen, $\gamma$-globulin and albumin, respectively at (a) $25^{\circ} \mathrm{C}$ known zeta potential $(-20 \mathrm{mV})$ in PBS that were run after each protein sample to show the protein samples were not having a direct effect on the pore walls themselves that may influence the recorded zeta potentials of future samples run on the same pore. Error bars are representative of the st.dev where $n=3$

function of incubation temperature between 25 and $37{ }^{\circ} \mathrm{C}$ $(5.0 \mathrm{mV})$, whereas albumin showed the smallest change $(1.3 \mathrm{mV})$. The distribution of zeta potentials for each isolated protein at 25 and at $37^{\circ} \mathrm{C}$ are shown in the ESM, Fig. S2.

The particle-by-particle nature of TRPS allows for individual particles to be analysed, as well providing a measure of the spread in values across the sample population. Figure 3 depicts the zeta potential versus particle size plots for the given sample populations summarised in Fig. 2. Note here that each data point in Fig. 3 is representative of a single particle.

Whilst the distribution of the values does not change as the incubation temperature increases, the shift in mean zeta potential as the incubation temperature was significant. This shift may be due to the affinities of the proteins for the particle surface being affected by the incubation temperature. Previous studies have found that negative particles have

\section{b}

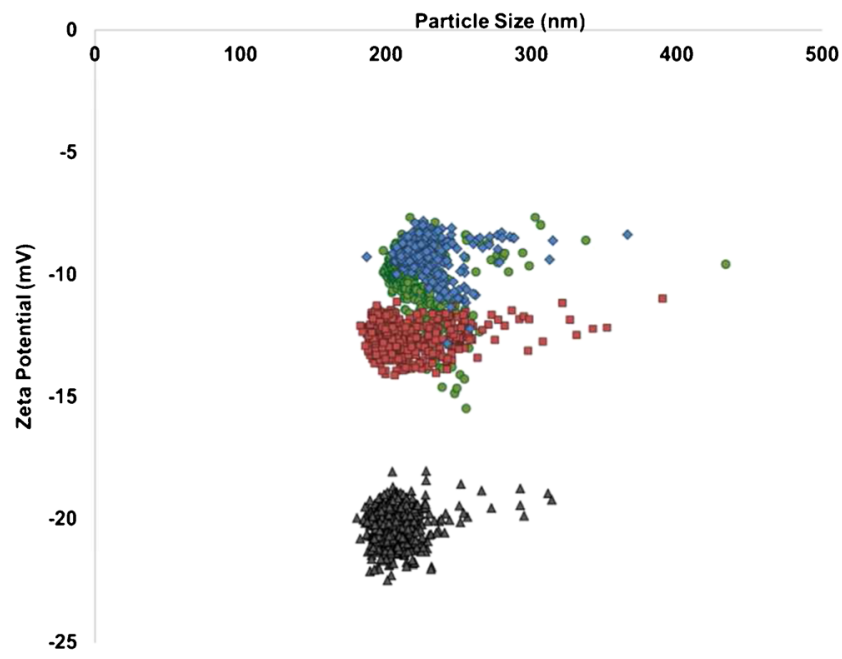

and (b) $37^{\circ} \mathrm{C}$. The black data points represent CPC200s in PBS for both figure parts $\mathbf{a}$ and $\mathbf{b}$ 
maximum protein adsorption at 15,35 and $37^{\circ} \mathrm{C}$ [67] and explain why the $\mathrm{CPC} 200$ s incubated at $37{ }^{\circ} \mathrm{C}$ in each protein medium shifted to a smaller zeta potential value more so than those incubated at $25^{\circ} \mathrm{C}$. When proteins have a higher affinity to the particle surface, there is either the formation of a robust hard corona, or slower release of the proteins from the surface once absorbed. The hard corona layer will alter the particle surface chemistry and will result in a slower particle translocation velocity through the pore due to shielding of the negative particle surface, which consequently results in a smaller zeta potential value. Interestingly, at the $25^{\circ} \mathrm{C}$ incubation (Fig. 3a), the $\gamma$-globulin and particularly the fibrinogen sample showed a wider spread of data than those samples incubated at $37{ }^{\circ} \mathrm{C}$ (Fig. 3b). Figure $3 \mathrm{~b}$ also shows that at elevated temperatures, a thicker protein corona layer is formed resulting in an increase in particle size. These results suggest the protein binding kinetics may differ as a function of temperature. The population spread may be wider at lower temperatures as the proteins may not have reached maximum levels of adsorption to the particle surface at $25^{\circ} \mathrm{C}$ [67], also supporting the small changes in mean zeta potential at $25^{\circ} \mathrm{C}$ demonstrated in Fig. 2.
Monitoring individual protein-nanoparticle interactions is interesting but becomes more complex in a medium containing a protein mixture, such as plasma or serum. Both plasma and serum are extracted from blood samples but contain a different composition of proteins. Relevant to this study, serum contains albumin, $\gamma$-globulin and apolipoproteins. Plasma has a similar protein composition to serum, but also contains clotting factors such as fibrinogen. Figure 4 shows the measured zeta potentials of CPC200s in PBS and of CPC200s incubated in plasma and serum for $10 \mathrm{~min}$ at both 25 and $37^{\circ} \mathrm{C}$.

As seen in the isolated fibrinogen and $\gamma$-globulin samples above, only small changes in zeta values were observed for both plasma and serum at $25^{\circ} \mathrm{C}$. Interestingly, at the elevated incubation temperature of $37^{\circ} \mathrm{C}$, the plasma still did not appear to show a significant difference in zeta potential, whereas the sample in serum showed a reduction in zeta potential of $5.9 \mathrm{mV}$. The most prominent difference between plasma and serum is the presence of clotting factors in plasma; this will have an inherent effect on the protein corona structure and resulting interactions with the particle surface [63]. Protein corona formation is complex in physiological environments
Fig. 4 (a) Mean zeta potential $(\mathrm{mV})$ versus incubation medium. Comparison of CPC200 particles incubated in PBS (green), plasma and serum for $10 \mathrm{~min}$ at $25^{\circ} \mathrm{C}$ (blue) and $37^{\circ} \mathrm{C} \mathrm{(red).} \mathrm{Error} \mathrm{bars}$ are representative of the st.dev where $n=3$. (b) Frequency (\%) versus zeta potential $(\mathrm{mV})$. Zeta potential distributions for CPC200s incubated for $10 \mathrm{~min}$ at $37^{\circ} \mathrm{C}$ in plasma (purple) and serum (pink). Repeat datasets for CPC200s incubated in both plasma and serum at $37^{\circ} \mathrm{C}$ for 10 min are illustrated in ESM

Fig. S3 and are compared to a zeta potential distribution of $\mathrm{CPC} 200 \mathrm{~s}$ in PBS only

\section{a}

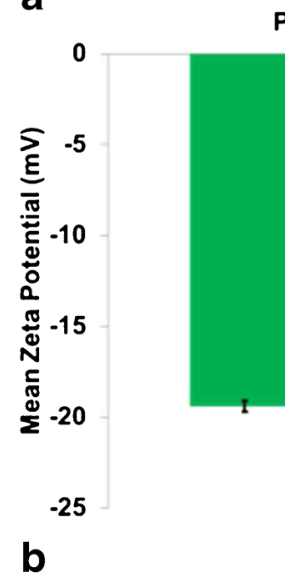

PBS

Plasma

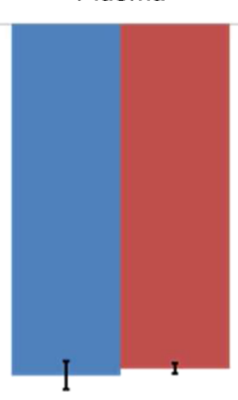

Serum

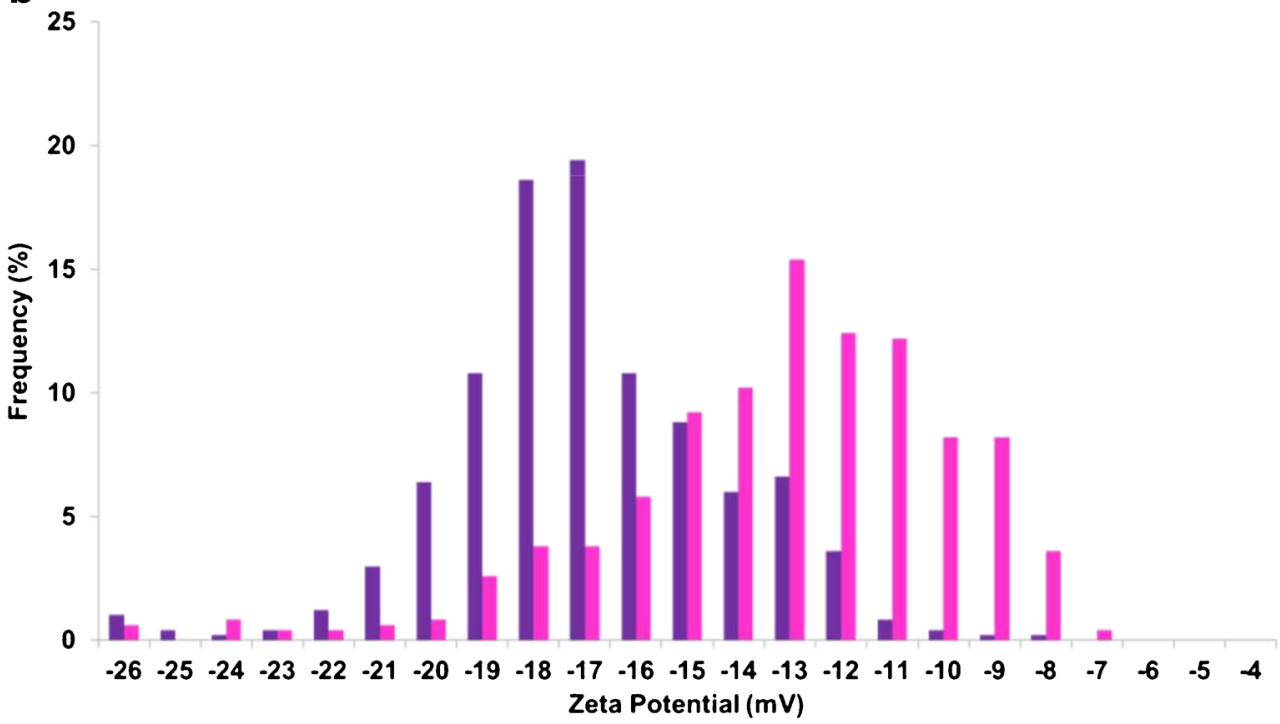


as it consists of the simultaneous binding of numerous proteins to the particle surface creating both protein-nanoparticle interactions as well as protein-protein interactions [63].

Proteins within plasma and serum are undergoing a competitive binding assay to the particle's surface, and proteins of higher concentration and/or affinity will bind to the particle surface more rapidly at the first instance. Protein-protein interactions are also common in plasma and serum samples, and some proteins will have a higher affinity to a subsequent protein over the particle surface. Zeta potential distribution as a function of temperature for the particles incubated with plasma and serum samples are shown in Fig. 5.

When the incubation temperature was increased, the zeta potential for both particles in plasma and serum were smaller. The advantage of distribution studies of a sample population is the discrete differences that can be identified, that cannot be determined immediately from mean values. For example, in Fig. 5a, the distribution shape of the particles incubated with plasma at $25^{\circ} \mathrm{C}$ (red) is almost twice as wide as the distribution for $37^{\circ} \mathrm{C}$ (purple), yet the mean values only changed by $0.4 \mathrm{mV}$ between temperatures, a negligible difference. The difference in distribution shape can be reflected using median skewness values. The median skewness values for a given sample population of particles incubated in plasma were 0.111 and -0.065 for incubation temperatures of 25 and $37{ }^{\circ} \mathrm{C}$, respectively. Particles in serum showed the same effect and as the incubation temperature was increased, the median skewness values decreased from $-0.105\left(25^{\circ} \mathrm{C}\right)$ to $-0.343\left(37^{\circ} \mathrm{C}\right)$.

The protein-nanoparticle interactions in plasma and serum were evidently varied, and to investigate this further, we completed a plasma spiking experiment. This aimed to ascertain if the soft corona formed in the plasma would reorganise in the presence of serum proteins. Figure 6 shows the effect on zeta potential as plasma $(5 \% \mathrm{~V} / \mathrm{V})$ was used to spike samples containing nanoparticles in serum at various time intervals.

Plasma protein adsorption onto a particle surface is due to the Vroman effect and is defined as the constant change in protein composition based on continuous adsorption and desorption at an interface [68]. There can be both faster and slower stages in this effect dependent on the protein. For example, albumin, $\gamma$-globulin and fibrinogen are all proteins that will adsorb rapidly onto a surface based on their high
Fig. 5 (a) Zeta potential distributions for $\mathrm{CPC} 200 \mathrm{~s}$ incubated in plasma for $10 \mathrm{~min}$ at $25^{\circ} \mathrm{C}$ (red) and $37^{\circ} \mathrm{C}$ (purple). (b) Zeta potential distributions for CPC200s incubated in serum for 10 min at $25^{\circ} \mathrm{C}$ (green) and $37^{\circ} \mathrm{C}$ (blue) a

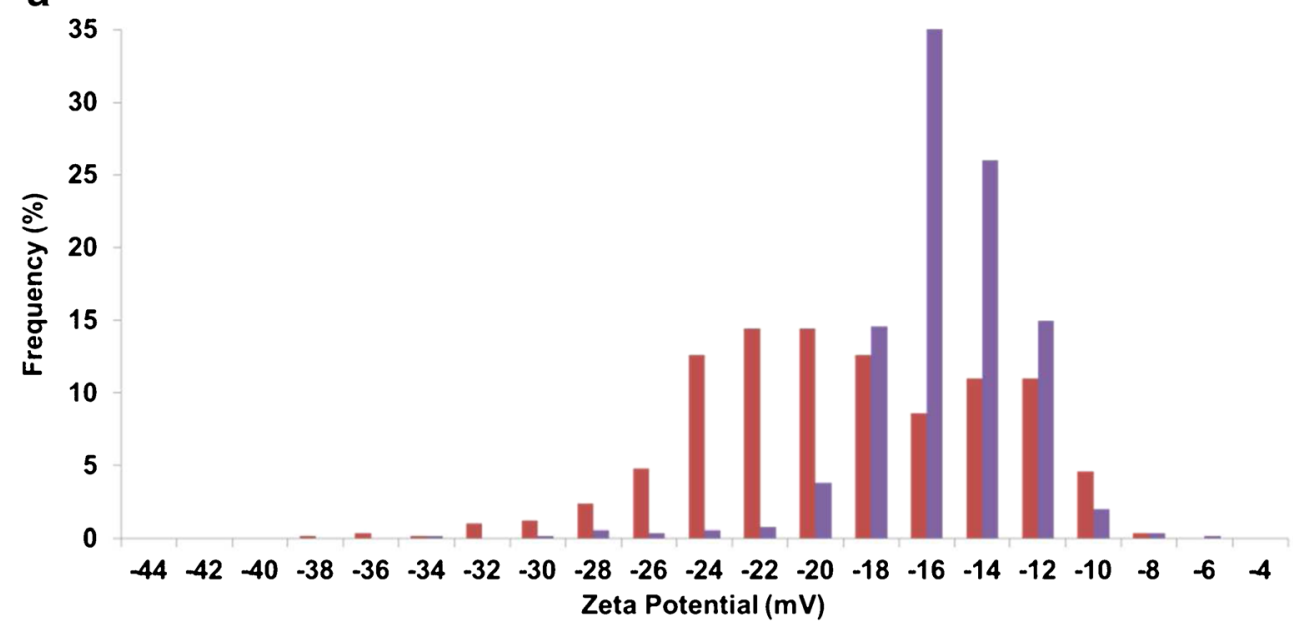

b

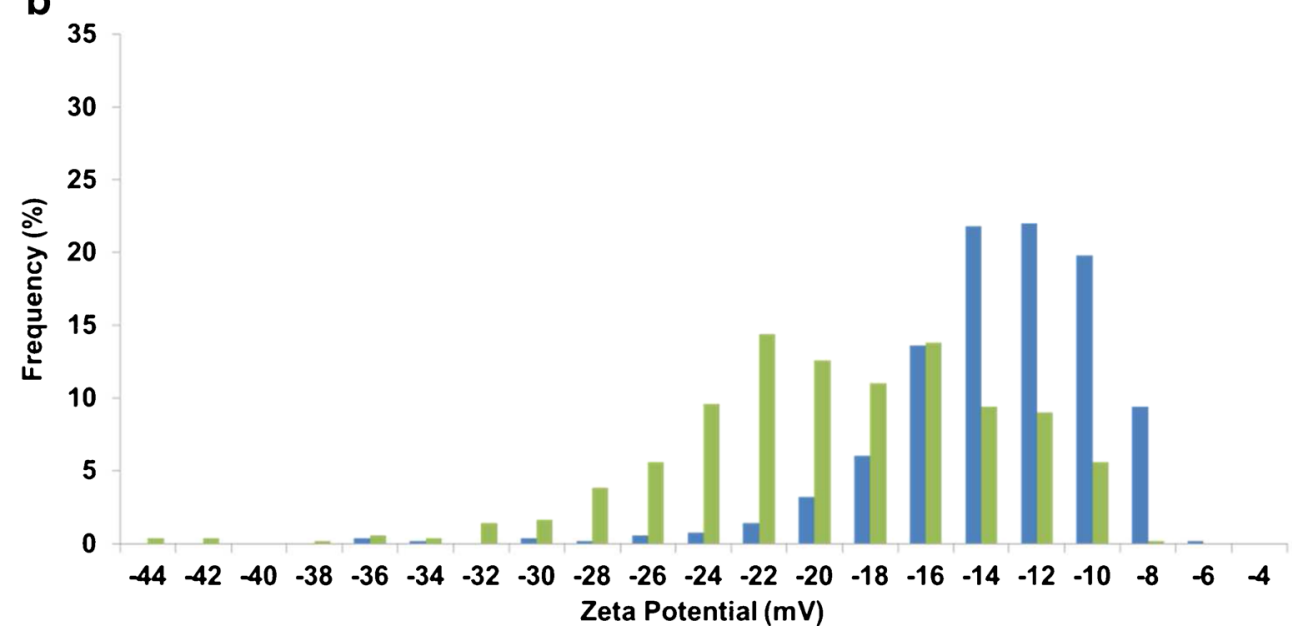


a
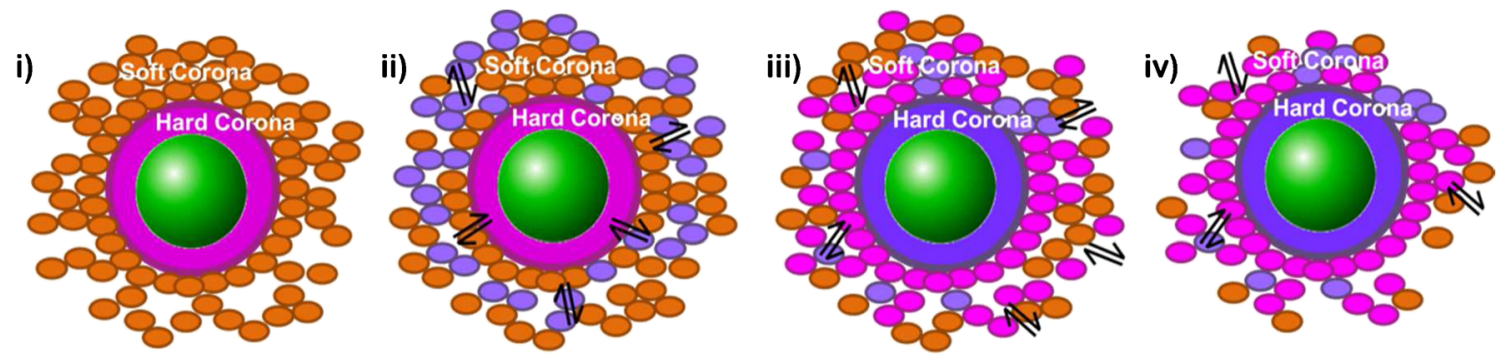

b

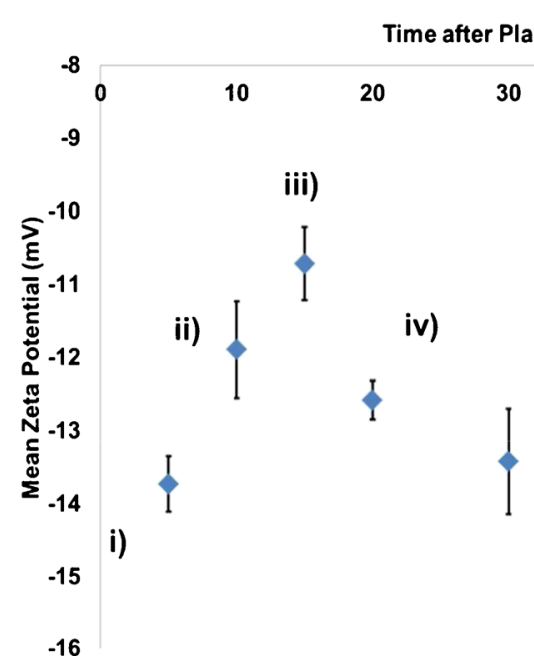

Fig. 6 The effect of spiking a sample of CPC200s incubated in serum with plasma. (a) Visual representation of the effect of protein displacement and exchange within a protein corona system. (i) Protein corona formed by particle incubation in serum, (ii) introduction of plasma proteins to sample, (iii) displacement of hard corona proteins due to proteins of higher affinities and exchange of soft corona proteins, (iv)

abundances, but are generally replaced by apolipoproteins in a matter of seconds [69] due to their fast dissociation properties. Apolipoproteins, however, although of low abundance, have a much slower dissociation constant and will therefore remain on the potential surface for longer [70]. As with a lot of nanoparticle-based assays, there may be an element of competition between proteins in binding to the nanoparticle surface that will affect the protein corona structure as displacement and exchange reactions may then take place over time. As the hard corona involves the higher affinitive proteins, this should remain adsorbed onto the nanoparticle surface over time and during any biophysical event that may occur [63]. The soft corona involves much weaker protein interactions in the system and will therefore dissociate more rapidly and protein exchange will occur much more readily. This effect is dependent on the relative protein concentrations of all proteins present in the plasma and serum samples. It is well known that protein concentration has a significant effect on the formation of a protein corona when incubated with nanoparticles [55, 71]; when a protein is of high concentration in a given sample, that protein will initially occupy the nanoparticle surface and form a protein corona [55] at a potentially faster rate than

Depletion of soft corona layer as proteins dissociate from loose proteinprotein interaction. (b) Particles were incubated in serum for $10 \mathrm{~min}$ and then spiked with $5 \%(v / v)$ plasma. Zeta potentials were measured at 5, 10, $15,20,30$ and $60 \mathrm{~min}$. (i)-(iv) indicate the shift in zeta potential as a result of the effects described in (a)

those of lower concentrations that may be later exchanged for those at a lower concentration but higher affinity. This effect also depends on the nanomaterial and there have been cases where proteins that have adsorbed first have had the longest residence time [72].

The first measurement was taken after the plasma had been introduced to the serum sample for $5 \mathrm{~min}$. Between 5 and $10 \mathrm{~min}$ of the plasma being present (Fig. 6(i-ii)), the zeta potential of the particles was reduced. This is due to the addition of proteins into the sample, a higher concentration of proteins interacting with the particles will result in a slower pore translocation velocity, hence the reduced zeta potential. Figure 6(iii) shows that after $15 \mathrm{~min}$, the zeta potential was reduced to its lowest measured value in this experiment. This is due to some of the plasma proteins displacing those from serum that may have reversibly bound to the particle surface as part of a hard corona layer. The plasma proteins may have been of a higher affinity to those present in the serum sample and therefore form the new hard corona layer [56, 62]. After $20 \mathrm{~min}$ and gradually onto $60 \mathrm{~min}$ (Fig. 6(iv)), the particle zeta potentials became more negative, indicating an increase in particle translocation velocity through the pore. We attribute 
this result to the weak interactions of the soft corona layers. For example, once the plasma proteins have potentially displaced those in the original hard corona, the displaced proteins will form part of the soft corona and be part of weaker protein-protein interactions. Over time, the soft corona proteins will dissociate more readily away from the particle due to their loose interactions [73], reducing the protein coverage around the particle and thus resulting in a larger zeta potential. The zeta potential becomes larger after this process as there are less bound proteins surrounding the particle to reduce the particle's translocation velocity. The faster the particle can traverse the pore, the larger the zeta potential value. This is of particular interest as it gathers valuable information on how the different compositions of plasma and serum proteins in a blood sample would affect a nanoparticle and how they behave differently when isolated and in a mixture.

\section{Conclusions}

We have demonstrated the effects of more prominent proteins found in protein coronas individually (isolated in PBS) and within their natural environment (within plasma and serum samples) on carboxylated polystyrene nanoparticle surfaces. Protein-nanoparticle interactions involved in the formation of a protein corona have been found to be protein dependent at $25{ }^{\circ} \mathrm{C}$, as well as temperature dependent for each studied protein. Significant changes in particle zeta potentials were observed when all of the proteins interacted with the nanoparticles at $37^{\circ} \mathrm{C}$. TRPS technology has enabled the provision of single particle analysis, as well as information on the zeta potential distributions amongst a given sample population in all experiments carried out, a more detailed insight than some other previously used ensemble techniques. We have found that although a stable hard and soft corona can be formed around particles in serum, we can also track various protein displacement and exchange processes occurring when plasma proteins are introduced to these samples. This has provided more detailed information on the affinities and reaction kinetics of protein coronas dependent on their biological medium and incubation conditions. A further understanding of protein-nanoparticle interactions in complex matrices and in physiological conditions is proving useful for advances in biotechnological assays and therapeutics.

Acknowledgments The authors thank Izon Science Ltd for their support, Peterborough City Hospital for the blood samples and Loughborough University. The work was supported by the European Commission for Research (PCIG11-GA-2012-321836 Nano4Bio) and the Peterborough City Hospital Haematology Research Fund. E.L.C.J.B. is supported by Izon Science Ltd and Loughborough University. EH was funded by the Analytical Science Trust fund for a summer studentship.

\section{Compliance with ethical standards}

Conflict of interest The authors declare no competing interests.

Human and animal rights and informed consent This work has been performed with the consent of healthy volunteers. The studies were approved by the ethics committee and performed in accordance of the ethical standards or Loughborough University.

Open Access This article is distributed under the terms of the Creative Commons Attribution 4.0 International License (http:// creativecommons.org/licenses/by/4.0/), which permits unrestricted use, distribution, and reproduction in any medium, provided you give appropriate credit to the original author(s) and the source, provide a link to the Creative Commons license, and indicate if changes were made.

\section{References}

1. Rolland JP, Maynor BW, Euliss LE, Exner AE, Denison GM, Desimone JM. Direct fabrication and harvesting of monodisperse, shape-specific nanobiomaterials. J Am Chem Soc. 2005;127(28): 10096-100.

2. Temer S, Zhong L, Travis C, Mostafa A. Shape-controlled synthesis of colloidal platinum nanoparticles. 1996;

3. Cuenya BR. Synthesis and catalytic properties of metal nanoparticles : size, shape, support, composition, and oxidation state effects. Thin Solid Films. 2010;518(12):3127-50. Elsevier B.V.

4. Perrault SD, Chan WCW. Synthesis and surface modification of highly monodispersed, spherical gold nanoparticles of 50-200 nm. 2009;17042-3.

5. Perrault SD, Walkey C, Jennings T, Fischer HC, Chan WCW. Mediating tumor targeting efficiency of nanoparticles through design. Nano Lett. 2009;9(5):1909-15.

6. Fang C, Shi B, Pei Y, Hong M, Wu J, Chen H. In vivo tumor targeting of tumor necrosis factor-loaded stealth nanoparticles : effect of MePEG molecular weight. 2005;7:27-36.

7. Soppimath KS, Aminabhavi TM, Kulkarni AR, Rudzinski WE. Biodegradable polymeric nanoparticles as drug delivery devices. J Control Release. 2001;70:1-20.

8. Hans ML, Lowman AM. Biodegradable nanoparticles for drug delivery and targeting. Curr Opin Solid State Mater Sci. 2002;6:31927.

9. Gupta AK, Wells S. Surface-modified superparamagnetic nanoparticles for drug delivery: preparation, characterization, and cytotoxicity studies. IEEE Trans Nanobioscience. 2004;3(1):66-73.

10. Llandro J, Palfreyman J, Ionescu A, Barnes C. Magnetic biosensor technologies for medical applications: a review. Med Biol Eng Comput. 2010;48(10):977-98. doi:10.1007/s11517-010-0649-3. Springer Berlin/Heidelberg.

11. Tokel O, Inci F, Demirci U. Advances in plasmonic technologies for point of care applications. Chem Rev [Internet]. American Chemical Society; 2014; Available from: http://dx.doi.org/10. 1021/cr4000623

12. Hupfield S, Holsaeter AM, Skar M, Frantzen CB, Brandl M. Liposome size analysis by dynamic/static light scattering upon size exclusion-/field flow fractionation. J Nanosci Nanotechnol 2006;6(7):3025-31.

13. Murdock RC, Braydich-stolle L, Schrand AM, Schlager JJ, Hussain $\mathrm{SM}, \mathrm{Al}$ MET. Characterization of nanomaterial dispersion in solution prior to in vitro exposure using dynamic light scattering technique. 2008;101(2):239-53.

14. Kozak D, Anderson W, Vogel R, Chen S. Simultaneous size and $\zeta$ potential measurements of individual nanoparticles in dispersion using size-tunable pore sensors. ACS Nano. 2012;6(8):6990-7. 
15. Anderson W, Kozak D, Coleman VA, Jämting ÅK, Trau M. A comparative study of submicron particle sizing platforms: accuracy, precision and resolution analysis of polydisperse particle size distributions. J Colloid Interface Sci [Internet]. (0). Available from: http://www.sciencedirect.com/science/article/pii/ S0021979713001756

16. Henriquez RR, Ito T, Sun L, Crooks RM. The resurgence of Coulter counting for analyzing nanoscale objects. Analyst. 2004;129(6): 478-82. doi:10.1039/B404251B. The Royal Society of Chemistry.

17. Kozak D, Anderson W, Vogel R, Trau M. Advances in resistive pulse sensors: devices bridging the void between molecular and microscopic detection. Nano Today [Internet]. 6(5):531-45. Available from: http://www.sciencedirect.com/science/article/pii/ S1748013211001010

18. Bayley H, Martin CR. Resistive-pulse sensing - from microbes to molecules. Chem Rev. 2000;100:2575-94.

19. Majd S, Yusko EC, Billeh YN, Macrae MX, Yang J, Mayer M. Applications of biological pores in nanomedicine, sensing, and nanoelectronics. Curr Opin Biotechnol. 2010;21(4):439-76. Elsevier Ltd.

20. Beckstein O, Sansom MSP. The influence of geometry, surface character, and flexibility on the permeation of ions and water through biological pores. Phys Biol. 2004;1(1-2):42-52.

21. Arjmandi N, Van Roy W, Lagae L, Borghs G. Measuring the electric charge and zeta potential of nanometer-sized objects using pyramidal-shaped nanopores. Anal Chem. 2012;84(20):8490-6. doi:10.1021/ac300705z. American Chemical Society.

22. Booth MA, Vogel R, Curran JM, Harbison S, Travas-Sejdic J. Detection of target-probe oligonucleotide hybridization using synthetic nanopore resistive pulse sensing. Biosens Bioelectron. 2013;45:136-40. Elsevier.

23. Dekker C. Solid-state nanopores. Nat Nanotechnol. 2007;2(4):20915.

24. Blundell ELCJ, Mayne LJ, Billinge ER, Platt M. Emergence of tunable resistive pulse sensing as a biosensor. Anal Methods. 2015. doi:10.1039/C4AY03023K. The Royal Society of Chemistry.

25. Billinge ER, Platt M. Aptamer based dispersion assay using tunable resistive pulse sensing (TRPS). Anal Methods. 2015;7(20):8534-8. doi:10.1039/C5AY01655J. The Royal Society of Chemistry.

26. Billinge ER, Broom M, Platt M. Monitoring aptamer-protein interactions using tunable resistive pulse sensing. Anal Chem. 2014;86(2):1030-7.

27. Billinge ER, Platt M. Multiplexed, label-free detection of biomarkers using aptamers and tunable resistive pulse sensing (AptaTRPS). Biosens Bioelectron. 2015;68:741-8.

28. Billinge ER, Muzard J, Platt M. Tunable resistive pulse sensing as a tool to monitor analyte induced particle aggregation. Nanomater Nanosci. 2013;1(1):1.

29. Platt M, Willmott GR, Lee GU. Resistive pulse sensing of analyteinduced multicomponent rod aggregation using tunable pores. Small. 2012;8(15):2436-44. doi:10.1002/smll.201200058. WILEY-VCH Verlag.

30. Roberts GS, Kozak D, Anderson W, Broom MF, Vogel R, Trau M. Tunable nano/micropores for particle detection and discrimination: scanning ion occlusion spectroscopy. Small. 2010;6(23):2653-8. doi:10.1002/smll.201001129. WILEY-VCH Verlag.

31. Roberts GS, Yu S, Zeng Q, Chan LCL, Anderson W, Colby AH, et al. Tunable pores for measuring concentrations of synthetic and biological nanoparticle dispersions. Biosens Bioelectron. 2012;31(1):17-25. Elsevier B.V.

32. Sowerby SJ, Broom MF, Petersen GB. Dynamically resizable nanometre-scale apertures for molecular sensing. Sensors Actuators B Chem. 2007;123(1):325-30. Available from: http:// www.sciencedirect.com/science/article/pii/S0925400506005740.

33. Vogel R, Willmott G, Kozak D, Roberts GS, Anderson W, Groenewegen L, et al. Quantitative sizing of nano/microparticles with a tunable elastomeric pore sensor. Anal Chem. 2011;83(9): 3499-506. doi:10.1021/ac200195n. American Chemical Society.

34. Willmott GR, Vogel R, Yu SSC, Groenewegen LG, Roberts GS, Kozak D, et al. Use of tunable nanopore blockade rates to investigate colloidal dispersions. J Phys Condens Matter. 2010;22(45): 454116.

35. Willmott GR, Platt M, Lee GU. Resistive pulse sensing of magnetic beads and supraparticle structures using tunable pores. Biomicrofluidics. 2012;6(1):14103-15.

36. Weatherall E, Willmott GR. Applications of tunable resistive pulse sensing. Analyst. 2015;140(10):3318-34. doi:10.1039/ C4AN02270J. The Royal Society of Chemistry.

37. Vogel R, Anderson W, Eldridge J, Glossop B, Willmott G. A variable pressure method for characterizing nanoparticle surface charge using pore sensors. Anal Chem. 2012;84(7):3125-31.

38. Blundell ELCJ, Vogel R, Platt M. Particle-by-particle charge analysis of DNA-modified nanoparticles using tunable resistive pulse sensing. 2015;

39. Sexton L, Horne L, Martin C. Biosensing with nanopores and nanotubes. In: Hayden O, Nielsch K, editors. Molecular- and nano-tubes SE - 6 [Internet]. Springer US; 2011. p. 165-207. Available from: 10.1007/978-1-4419-9443-1_6

40. Bayley H, Martin CR. Resistive-pulse sensingfrom microbes to molecules. Chem Rev. 2000;100(7):2575-94. doi:10.1021/ cr980099g. American Chemical Society.

41. Ioppolo JA, Bhadbhade M, Fox MA, Rendina LM. Remarkable cage deboronation and rearrangement of a closo-1,12dicarbadodecaborane to form a neutral nido-7,9dicarbaundecaborane. Chem Commun [Internet]. The Royal Society of Chemistry; 2013; Available from: 10.1039/ C3CC41173G

42. Sikora A, Bartczak D, Gei[German sz ligature\}ler D, Kestens V, Roebben G, Ramaye Y, et al. A systematic comparison of different techniques to determine the zeta potential of silica nanoparticles in biological medium. Anal Methods [Internet]. The Royal Society of Chemistry; 2015;7(23):9835-43. Available from: 10.1039/ C5AY02014J.

43. Sikora A, Shard AG, Minelli C. Size and $\zeta$-potential measurement of silica nanoparticles in serum using tunable resistive pulse sensing. Langmuir. 2016;32(9):2216-24. doi:10.1021/acs.langmuir. 5b04160. American Chemical Society.

44. Lane RE, Korbie D, Anderson W, Vaidyanathan R, Trau M. Analysis of exosome purification methods using a model liposome system and tunable-resistive pulse sensing. Sci Rep. 2015;5:7639. doi:10.1038/srep07639. The Author(s).

45. Pal AK, Aalaei I, Gadde S, Gaines P, Schmidt D, Demokritou P, et al. High resolution characterization of engineered nanomaterial dispersions in complex media using tunable resistive pulse sensing technology. ACS Nano. 2014;8(9):9003-15. doi:10.1021/ nn502219q. American Chemical Society.

46. Monopoli MP, Walczyk D, Campbell A, Elia G, Lynch I, Baldelli Bombelli F, et al. Physical-chemical aspects of protein corona: relevance to in vitro and in vivo biological impacts of nanoparticles. $\mathrm{J}$ Am Chem Soc. 2011;133(8):2525-34.

47. Flanagan MB, Lundqvist M, Stigler J, Cedervall T, Bergga T. The evolution of the protein corona around nanoparticles : a test study. 2011;(9):7503-9.

48. Pozzi D, Caracciolo G, Digiacomo L, Colapicchioni V, Palchetti S, Capriotti AL, et al. The biomolecular corona of nanoparticles in circulating blood media. Nanoscale. 2015;7:13958-66.

49. Cedervall T, Lynch I, Lindman S, Berggård T, Thulin E, Nilsson H, et al. Understanding the nanoparticle-protein corona using methods to quantify exchange rates and affinities of proteins for nanoparticles. Proc Natl Acad Sci. 2007;104(7):2050-5.

50. Sakulkhu U, Mahmoudi M, Maurizi L, Salaklang J, Hofmann H. Protein corona composition of superparamagnetic iron oxide 
nanoparticles with various physico-chemical properties and coatings. Sci Rep. 2014;4:5020.

51. Ritz S, Scho S, Kotman N, Baier G, Musyanovych A, Kuharev J, et al. Protein corona of nanoparticles: distinct proteins regulate the cellular uptake. Biomacromolecules. 2015;16:1311-21.

52. Tenzer S, Docter D, Kuharev J, Musyanovych A, Fetz V, Hecht R, et al. Rapid formation of plasma protein corona critically affects nanoparticle pathophysiology. Nat Nanotechnol. 2013;8:772-81.

53. Lundqvist M, Stigler J, Elia G, Lynch I, Cedervall T, Dawson KA. Nanoparticle size and surface properties determine the protein corona with possible implications for biological impacts. 2008;105(38):14265-70.

54. Lundqvist M, Stigler J, Elia G, Lynch I, Cedervall T, Dawson KA. Nanoparticle size and surface properties determine the protein corona with possible implications for biological impacts. Proc Natl Acad Sci. 2008;105(38):14265-70.

55. Cedervall T, Lynch I, Foy M, Berggård T, Donnelly SC, Cagney G, et al. Detailed identification of plasma proteins adsorbed on copolymer nanoparticles. Angew Chem Int Ed Engl. 2007;46:5754-6.

56. Walczyk D, Bombelli FB, Monopoli MP, Lynch I, Dawson KA. What the cell "Sees" in bionanoscience. J Am Chem Soc. 2010;132(19):5761-8.

57. Lacerda SHDP, Park JJ, Meuse C, Pristinski D, Becker ML, Karim $\mathrm{A}$, et al. Interaction of gold nanoparticles with common human blood proteins. ACS Nano. 2010;4(1):365-79.

58. Deng ZJ, Liang M, Monteiro M, Toth I, Minchin R. Nanoparticleinduced unfolding of fibrinogen promotes Mac-1 receptor activation and inflammation. Nat Nanotechnol. 2011;6(1):39-44.

59. Lindman S, Lynch I, Thulin E, Nilsson H, Dawson KA, Linse S. Systematic investigation of the thermodynamics of HSA adsorption to N-tert-butylacrylamide copolymer nanoparticles. Effects of particle size and hydrophobicity. Nano Lett. 2007;7(4):914-20.

60. Casals E, Pfaller T, Duschl A, Oostingh GJ, Puntes V. Time evolution of the nanoparticle protein corona. 2010;4(7):3623-32.

61. Clogston J, Patri A. Zeta potential measurement. In: McNeil SE, editor. Characterization of nanoparticles intended for drug delivery SE - 6 [Internet]. Humana Press; 2011. p. 63-70. Available from: 10.1007/978-1-60327-198-1_6
62. Lynch I, Cedervall T, Lundqvist M, Cabaleiro-lago C, Linse S, Dawson KA. The nanoparticle-protein complex as a biological entity; a complex fluids and surface science challenge for the 21st century. Adv Colloid Interface Sci. 2007;135:167-74.

63. Walkey CD, Chan WCW. Understanding and controlling the interaction of nanomaterials with proteins in a physiological environment. Chem Soc Rev. 2012;41(7):2780-99.

64. Röcker C, Pötzl M, Zhang F, Parak W, Nienhaus G. A quantitative fluorescence study of protein monolayer formation on colloidal nanoparticles. Nat Nanotechnol. 2009;4(9):577-80.

65. Bhat SV, Nagasampagi BA, Meenakshi S. Chemistry of natural products. Berlin: Springer; 2005. 343 p.

66. Tengvall P, Lundstrom I. Molecular packing of HSA, IgG, and fibrinogen adsorbed on silicon by AFM imaging. 1998;

67. Mahmoudi M, Shokrgozar MA, Behzadi S. Slight temperature changes affect protein affinity and cellular uptake/toxicity of nanoparticles. Nanoscale. 2013;5:3240-4.

68. Vroman L, Adams AL, Fischer GC, Munoz PC. Interaction of high molecular weight kininogen, factor XII, and fibrinogen in plasma at interfaces. Blood. 1980;55(1):156-9.

69. Blunk T, Lück M, Calvor A, Hochstrasser DF, Sanchez JC, Müller BW, et al. Kinetics of plasma protein adsorption on model particles for controlled drug delivery and drug targeting. Eur J Pharm Biopharm. 1996;42(4):262-8.

70. Orco DD, Lundqvist M, Oslakovic C, Cedervall T, Linse S. Modeling the time evolution of the nanoparticle-protein corona in a body fluid. PLoS One. 2010;5(6):1-8.

71. Aggarwal P, Hall JB, Mcleland CB, Dobrovolskaia MA, Mcneil SE. Nanoparticle interaction with plasma proteins as it relates to particle biodistribution, biocompatibility and therapeutic efficacy. Adv Drug Deliv Rev. 2009;61(6):428-37. Elsevier B.V.

72. Harnisch S, Müller RH. Adsorption kinetics of plasma proteins on oil-in-water emulsions for parenteral nutrition. Eur J Pharm Biopharm. 2000;49:41-6.

73. Milani S, Bombelli FB, Pitek AS, Dawson KA. Reversible versus Irreversible binding of transferrin to polystyrene nanoparticles : soft and hard corona. 2012;(3):2532-41. 